\title{
The Characterization of Energy Absorption and Failure Response of Square Paper Tube by Quasi Static Axial Compression Test
}

\author{
Jie-Shing Lo*, Quoc-Hung Phan and Dun Yi Wang \\ Department of Mechanical Engineering, National United University, Taiwan
}

*Corresponding author: Jie-Shing Lo, Department of Mechanical Engineering, National United University, Miao-Li 36063, Taiwan R.O.C.

\begin{abstract}
The characterization of mechanical and energy absorption properties of the square paper tube is performed by using the quasi static axial compression test. In the proposed technique, four square paper tubes with various widths of $60 \mathrm{~mm}, 65 \mathrm{~mm}, 75 \mathrm{~mm}, 80 \mathrm{~mm}$, and same nominal thickness $2.75 \mathrm{~mm}$, are tested. The load-displacement curve is used for analyzing the buckling failure modes. The results show that the buckling failure initiates at the top end and mid-length of the tube varies with the width of the square tubes. The peak compressive load/energy absorption of the specimens with different width are studied. The results show that the peak compressive load decreases while the energy absorption increases with the increase of the compression stroke. Furthermore, the results also show that the crush force efficiency, the specific absorption energy, and the maximum compression stress decreases with the width of square paper tubes. In general, this study provides a useful information of mechanical and energy absorption properties of square paper tubes and its application as an energy absorber.
\end{abstract}

Keywords: Square paper tubes; Quasi static axial compression; Buckling failure; Absorption energy

\section{Introduction}

In recent years, due to the rise of environmental awareness, product from paper attracted scientist with its capable of low environmental impact and recyclability. The paper structure inherent a good energy absorption, easy manufacturing, light weight, and low cost. Thus, it has been widely used for absorber, cushion structures, protective packaging, and construction engineering. Many techniques have been proposed for paper products manufacturing [1-5] and many temporary or semipermanent paperboard tube structures have been proposed for exhibition spaces, humanitarian emergency shelters, single family houses, partition systems and even bridges [6-7]. The paperboard tube structures have been treated with moisture penetration, structural components and joints conducted structural analysis to ensure appropriate structural stability, safety, and serviceability [89].
Paper is generally considered to be an orthotropic, nonlinear viscoelastic materials that also exhibits sensitive response when exposed to changing humidity conditions. Spiral paper tubes are manufactured using a sophisticated process. When paper ply spirally winded, the paper tube becomes an anisotropic structure as the principal directions of the paper are not aligned with the principal directions of the tube. This property complicates the conditions of the manufacturing operations and make it difficult to analyze the loading properties for the paper tubes [10]. Paper tube materials are becoming more and more widely used, but the properties and application characteristics of the paper tube materials have not completely evident. Moreover, the compressive load of paper tube played an important role in its applications. Gerhardt [11] confirmed that under external pressure loading, deformations of paper tubes was quite different from those discovered in isotropic 
materials. Beatty and Cheng [12] showed that laminated tube was free to rotate, and the axial loading induced a torsional twist about the tube axis. It was also found that when the axial compressive force achieved a maximum value, the cylinder walls was buckle by folding inward along the helical fiber lines of the tube. Czechowski et al. [13] modelled the paper as an orthotropic material subjected to transversal compressive force to analyze the failure properties of pipes. Cai et al. [14] confirmed that buckles were occurred locally beneath the center of the load or extended to edge of the load when the cylindrical shells subjected to the non-uniform axial compressive stress. The study also confirmed that the buckling mode was strongly affected by the induced shear stress associated with the edge of the load and the ratio of the thickness $(t)$ and the width $(\mathrm{w})$ of the tube.

Hull [15] confirmed that the composite materials had superior performance on crashworthiness characteristics and energy absorption capability. These results had inspired others to do further investigation on crashworthiness characteristics of composite materials and relative applications [16-18]. On the other hand, square tube performed more advantage on crashworthiness characteristics and energy absorption capability [19-21]. Lian et al. [22] investigated the collapse behavior of square paper tubes and the influence of tensile-compressive yield asymmetries theoretically and experimentally. This study obtained a good agreement between the theoretical and experimental results by taking account of effective crushing distance into the calculation. In this study, the load-displacement response, crashworthiness characteristics and energy absorption capability of the square paper tube subjected to quasi-static axial compressive load were investigated. The failure modes were studied using the load-displacement curves at step of compression test.

A further study on the absorption energy and peak compressive load of specimens with various widths of 60 ,

65, 70, $80 \mathrm{~mm}$ were performed.

\section{Sample and Quasi Static Axial Compression Test}

The schematic diagram of a square paper tube is shown in Figure 1. As shown, the square paper tube was made of six plies of Kraft Paper, glued together with adhesive application to each ply, and then spirally wound the ply paper on the square mandrel to make of the paper tube continuously by the processing machine. The six plies of Kraft included one outer, one inner liner Kraft and four plies of medium Kraft. The densities of outer and inner liner Kraft were 240 g/m3, medium Kraft was 440 g/m3. The measured average density of the overall test specimens was $0.824 \mathrm{~g} / \mathrm{cm}^{3}$. This density was lower than of natural and synthetic fiber such as: silk, hemp, jute, cotton, carbon and Kevlar fiber [20]. When performing the experiment, four square paper tube specimens with various widths namely C60, C65, C75, and C80 were prepared.

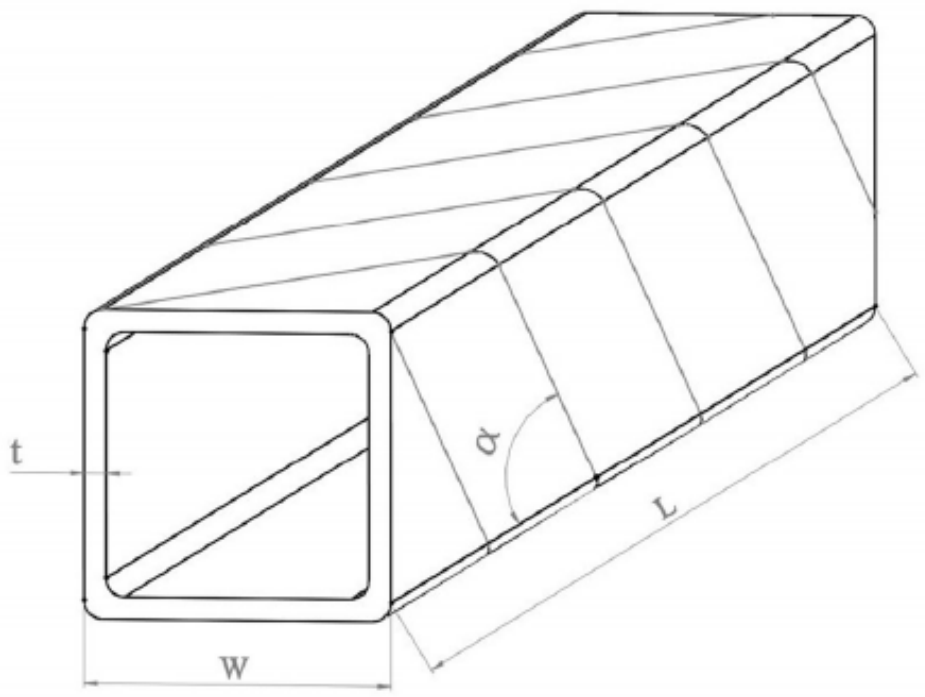

Figure 1: Schematic diagram of a square paper tube.

The test specimens were performed according to ASTM695 standard. The various specifications are shown in Table 1. The flatness, the verticality of the end face and axis were carefully made to prevent irregular deformation during the experiment process. The static axial compression tests were performed by universal test machine (HT-9160, Hung Ta Instrument Co., Taichung, Taiwan) with $30 \mathrm{kN}$ loading capacity. The tests were performed in quasistatic conditions at constant cross head speed $15 \mathrm{~mm} / \mathrm{min}$. The total compression stroke was 0.3 times the length of the test specimen. The quasi static experimental was conducted under condition of relative humidity (RH) $50 \%$ and temperature $22{ }^{\circ} \mathrm{C}$. The compression test for each specimen was repeated 5 times. 
Table 1: Specification of the specimens.

\begin{tabular}{|c|c|c|c|c|c|c|}
\hline Specimen & (L) $(\mathbf{m m})$ & $(\mathbf{W})(\mathbf{m m})$ & $(\mathbf{t})(\mathbf{m m})$ & $(\mathbf{A})\left(\mathbf{m m}^{2}\right)$ & $(\boldsymbol{\alpha})(\mathbf{d e g})$ & $\mathbf{t} / \mathbf{W}$ \\
\hline C60 & 59.58 & 60.41 & 2.76 & 636.46 & 28.22 & 0.0457 \\
\hline C65 & 65.98 & 67.22 & 2.98 & 765.74 & 25.5 & 0.0443 \\
\hline C75 & 75.56 & 75.61 & 2.71 & 790.24 & 20.95 & 0.0358 \\
\hline C80 & 79.9 & 80.62 & 2.76 & 859.57 & 19.73 & 0.0342 \\
\hline
\end{tabular}

\section{Results and Discussion}

The load-displacement curve schematic of square paper tube obtained by quasi-static axial compression is shown in Figure 2. As shown, the curve is divided into three main zones namely the pre-crushing zone, post-crushing zone, and compact zone. At the pre-crushing zone, the load varies linearly with the displacement and terminated at the initiation of failure caused by peak load. At the post-crushing zone, the peak load break over the yield strength and initiated crushing the specimens. The load-displacement curve displays a significant load drop. Finally, at the compact zone, the load increases rapidly because the squeezing of the failure paper tube at the end of the compression stroke.

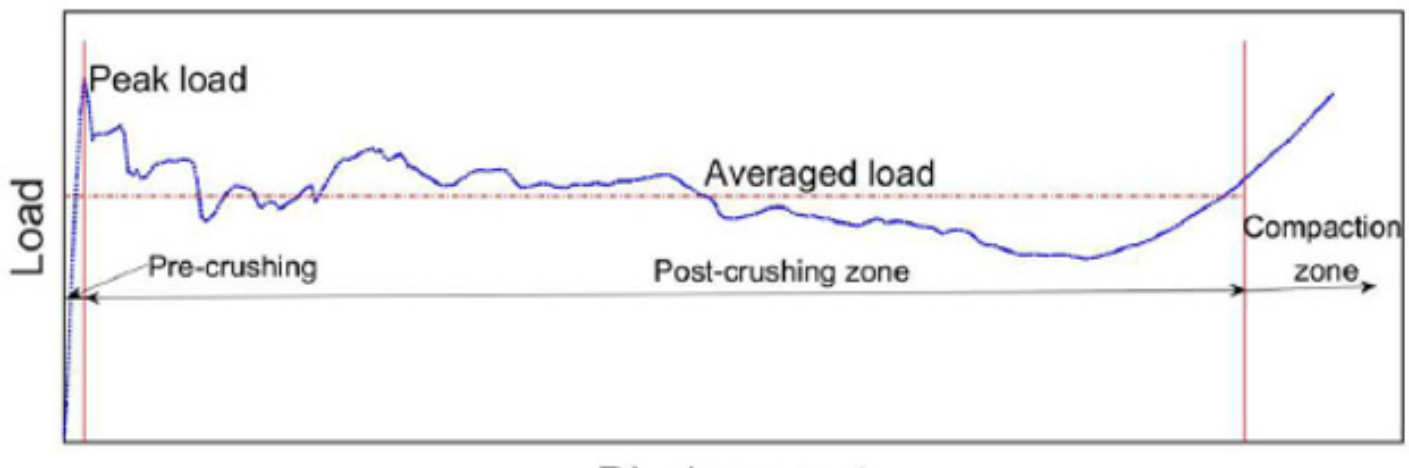

Displaecment

Figure 2: Load-displacement curve of full stroke compression.

Figures 3-5 describe the buckling failure modes of the specimens under quasi static compression test. After peak load breaking the yield strength, the paper crash was induced. The initial crash will cause the catastrophic failure and induced buckling failure. The buckling failure is classified into three main types namely top-end, mid-length and bottom-end buckling failure. Figure 3 shows the top end buckling failure of the specimen under quasi static compression test. As shown in Figure 3a, the buckling failure starts at the top end position (Figure 3a1), keep continuing propagate downward (Figure 3a2-3), and finally, terminates at a certain distance from the top end (Figure 3a4). As shown in Figure 3b, the first and second peak loads appear sequentially (the pre-crush zone). The curve presents a rapid drop of the load right after reaching the peak load (the post crush zone). Finally, the load is stable at the compaction zone. Figure 4 shows the mid-length buckling failure of the specimens under quasi static compression test. As shown in Figure $4 \mathrm{a}$, the crack initiates at the middle length of specimen at the paper plies butted place along the winding direction. The crash zone propagation then continues and wind around the corners of paper tube. As shown in Figure $4 \mathrm{~b}$, at the pre-crushing zone, the load varies linearly with the displacement until the peak load point. The load then drops suddenly at the post crush zone. The paper crash keeps continuing and the load decreases linearly with the increase of displacement at the compact zone. It is noted that the number 1-4 in Figure 4a correspond to the red-vertical line presented in Figure 4b. Figure 5 shows the bottom-end buckling failure of the specimens under quasi static compression test. As shown in Figure 5a, the buckling failure starts near the bottom of the specimen (Figure 5a1), keep continuing propagate downward (Figure 5a2-3), finally, terminates at the bottom of the specimen (Figure 5a4). Furthermore, the crack zone propagates along the corner edges and wind around the corner of the specimen to form a circumferential fracture and bend the wall. As shown in Figure 5b, the load varies linearly with the displacement at the pre-crushing zone present. There are two peak loads in the pre-crushing zone. A sudden load drop is presented at the pre-crushing zone and remain stable at the combat zone.

Figure 6 shows the image at the end section of the specimen under quasi static compression test. As shown in Figure 6a (front view), the failure is formed at the bottom position of the specimens. As shown in Figure 6b (top view), the minor delamination occurs between the paper layers. Since the failure is formed at the bottomend of the specimen thus the delamination at the top-end is 
reduced. As shown in Figure 6c (bottom view), the delamination at the bottom end position is obvious and serious. The results confirm that the collapse failure is mainly caused by buckling and delamination. Furthermore, the specimen has the characteristics of a ductile material thus withstand a long-stroke destructive compression.
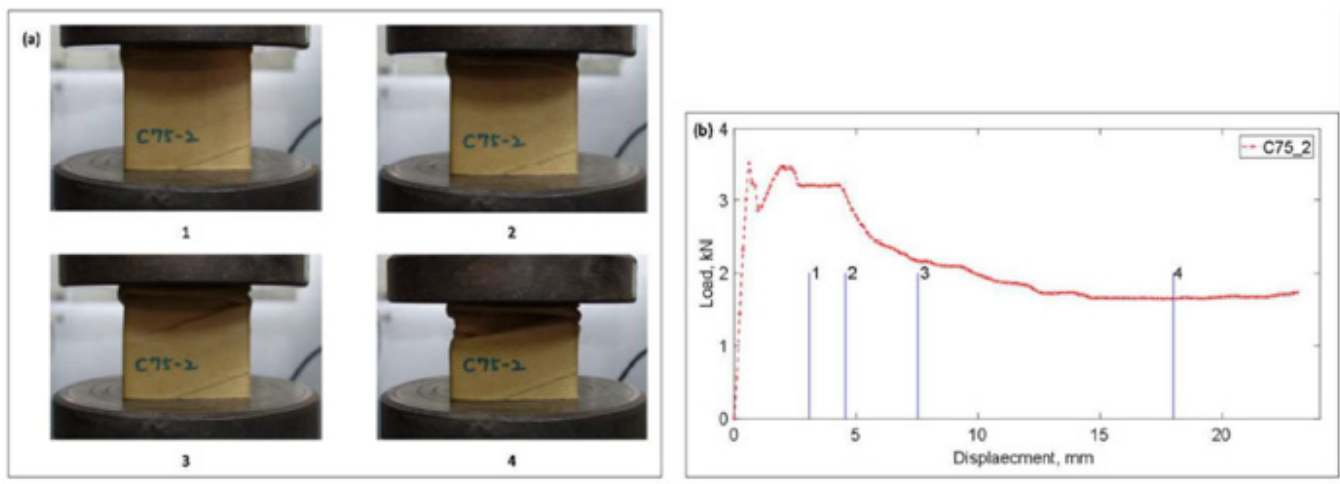

Figure 3: Example of mid-length buckling failure, (a) photographs of different steps of compression test, (b) diagram of load-displacement.
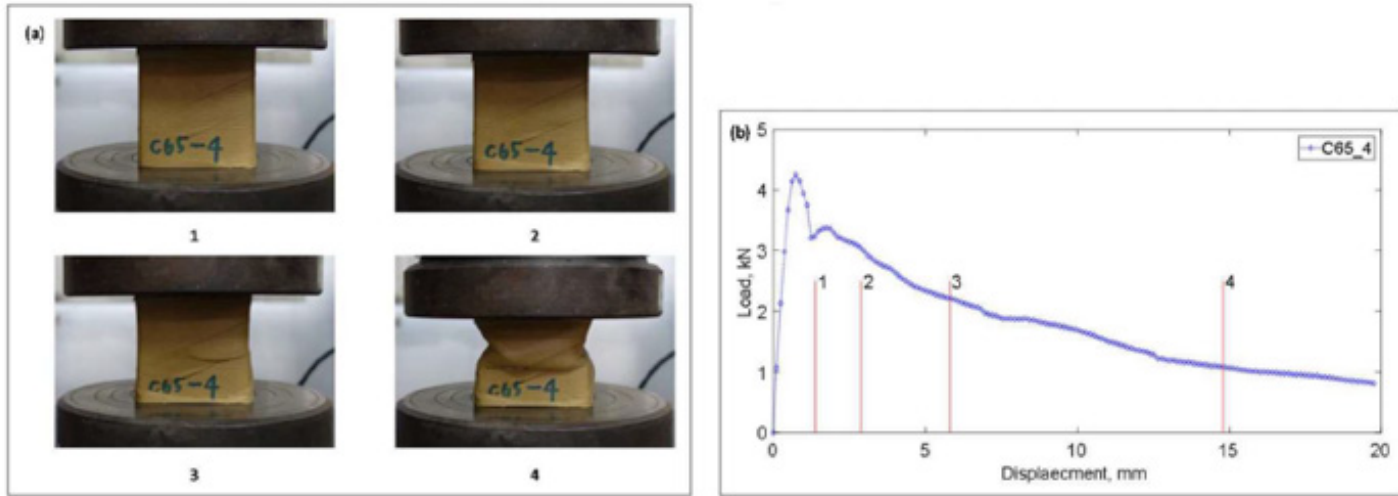

Figure 4: Results of load buckling failure at mid-length: (a) with different steps and (b) the schematic of load displacement curve.
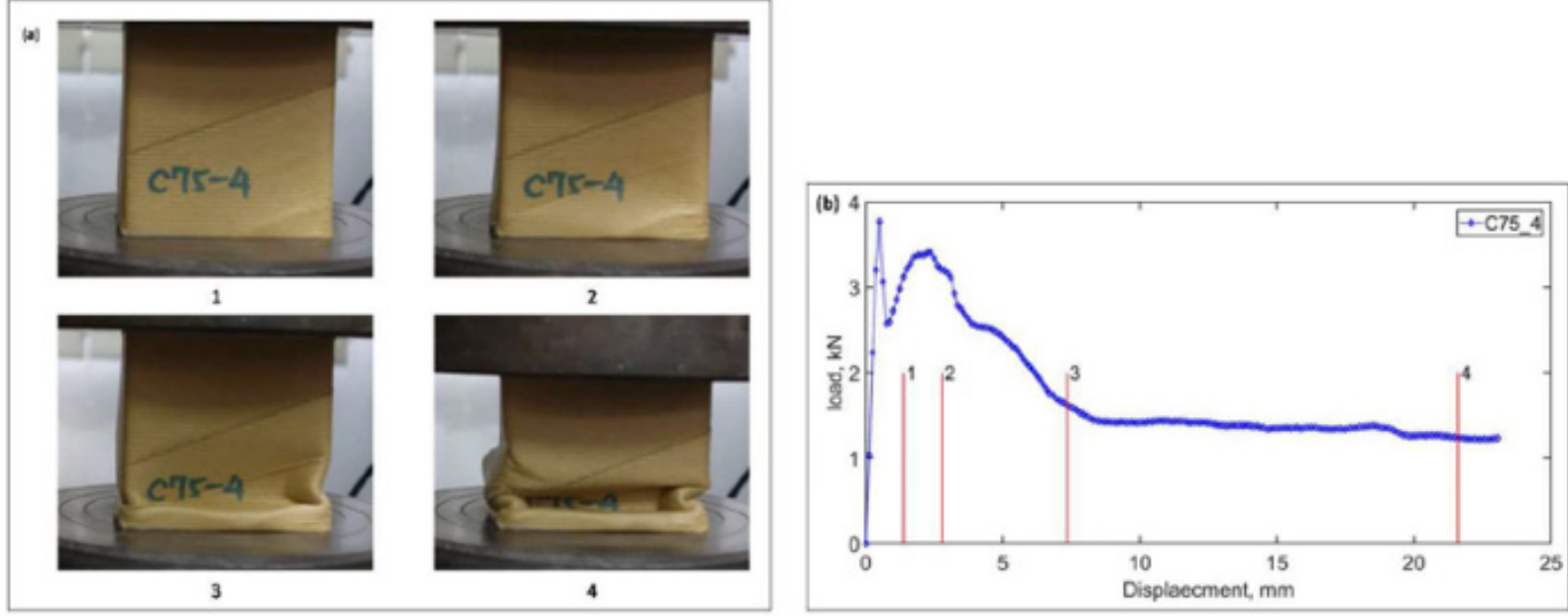

Figure 5: Results of load buckling failure at bottom end: (a) photographs of different steps of compression test,(b) diagram of load displacement. 

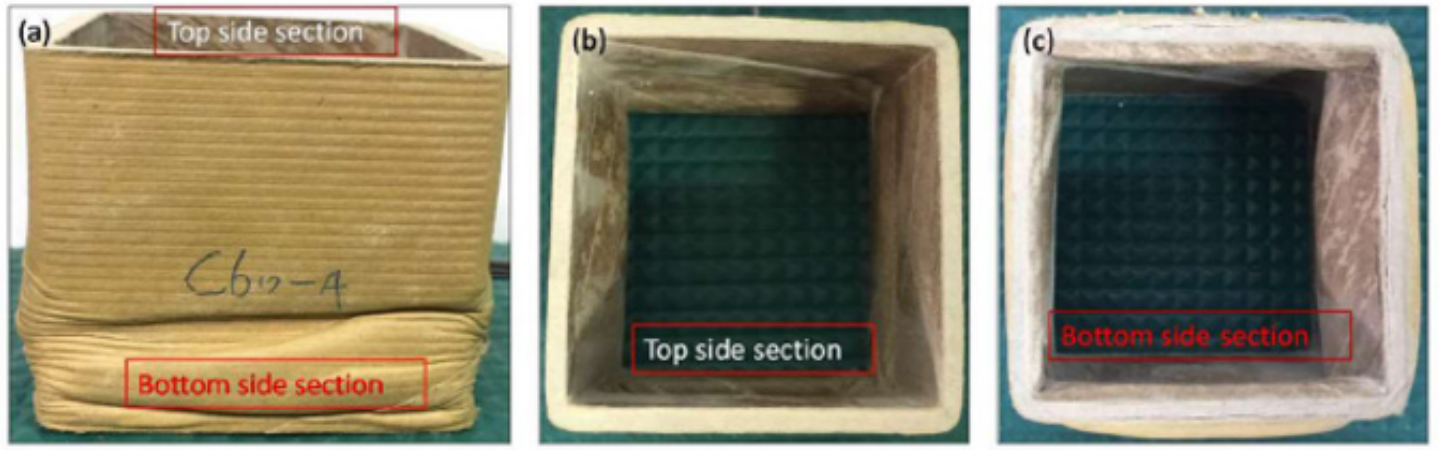

Figure 6: Delamination feature of square paper tube by buckling failure (a) front view, (b) top view, and (c) bottom view.

Figure 7 shows the load-displacement curves of square paper tubes with four various widths of $60 \mathrm{~mm}, 65 \mathrm{~mm}, 75 \mathrm{~mm}$, and 80 $\mathrm{mm}$. As shown in Figure 7a-c, the second peak load is appeared, and the curves are wind and twist. As show in Figure 7d, only one peak load is formed, and the load-displacement curves are smoother than that of show in Figure 7a-c. The results show that the second load peak is formed only for the specimens with the width less than
$80 \mathrm{~mm}$. Furthermore, as shown in Figure 7d, the specimen endures a longer displacement to reach the peak load position. The peak load value is lower than that of show in Figure $7 \mathrm{a}-\mathrm{c}$. In other word, the specimen is easily damaged by a smaller load. The $t / w$ ratio of the C80 samples is smaller than other specimens. Thus, the $\mathrm{t} /$ $\mathrm{w}=0.355$ is the critical value of the square paper tube structure.
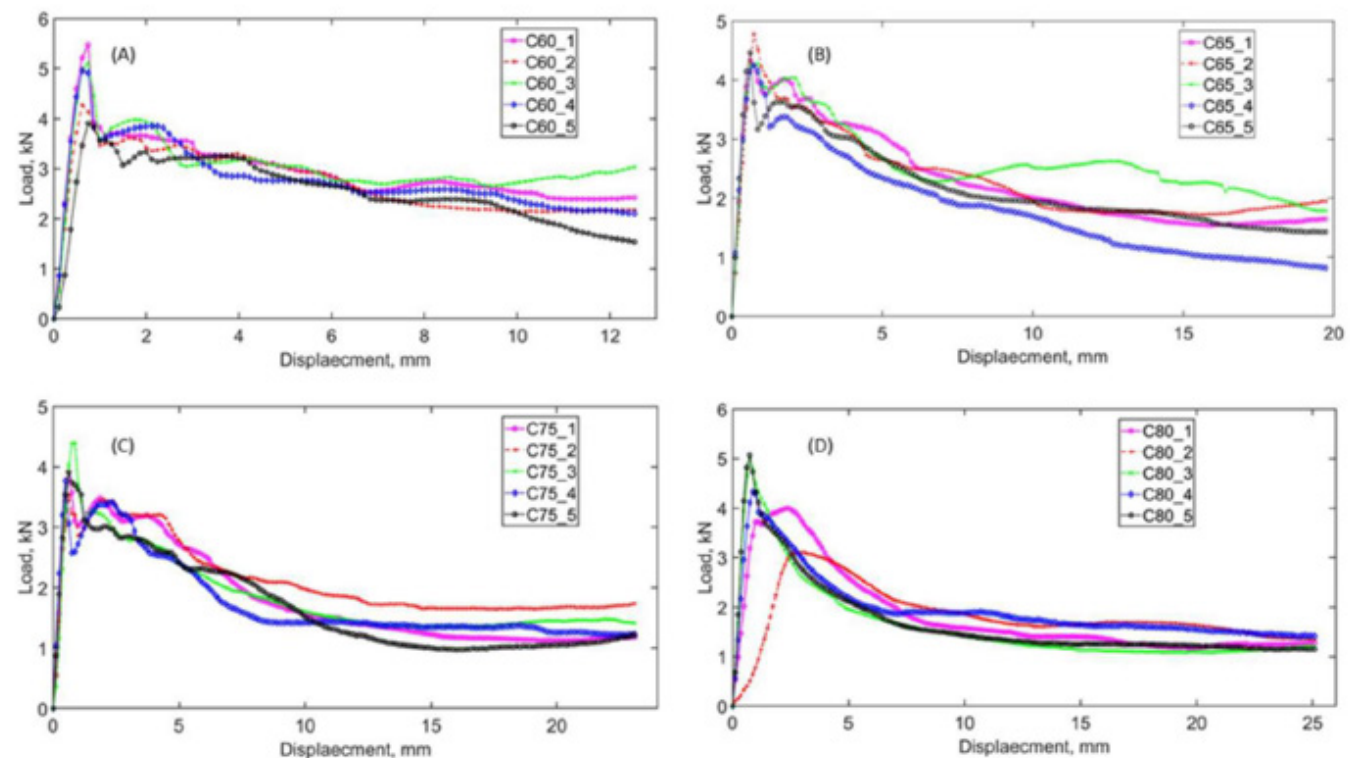

Figure 7: Load-displacement curves of specimens with different outer width.

Figure 8 shows the results of absorbed crash energy (E) of four specimens. Absorbed crash energy (E) is defined by the area under the load-displacement curve. As shown, for the same amount of $\mathrm{E}$, the wider specimen requires higher displacement. The displacement is about $12.3,20,24$, and $25.3 \mathrm{~mm}$ for the specimens of $\mathrm{C} 60, \mathrm{C} 65, \mathrm{C} 75$, and C80, respectively. It is noted that the vertical red line is the displacement stroke of C60.The absorbed crash energy (E) and peak compressive load of full and constant stroke of specimens is showed in Figure 9. The average peak compressive load $\left(P^{-}\right)$is calculated from averaging the peak load of the postcrush region. The average load describes the resistant capability of the specimen under failure propagation. As shown, the average absorbed crash energy increases as the specimen width increases (Figure 9a). While the peak compressive load decreases with the specimen width (Figure 9b). Because the specimen with the larger width have longer stroke that increased absorbed crash energy (E) even with a smaller peak compressive load. As shown in Figure 9a, for the full stroke, E increases $26.53 \%$ and the peak compressive 
load decreases $10.37 \%$ as the width increases from C60 to C80. The average deviation of the results of the absorbed crash energy and peak compressive load over 5 repeated tests are $2.44 \mathrm{~J}$ and $3.29 \mathrm{~J}$, respectively.

For the constant stroke, $\mathrm{E}$ and the peak compressive load decreases $21.67 \%$ and $38.43 \%$, respectively, as the width increases from C60 to C80. The average deviation of the results of the absorbed crash energy and peak compressive load over 5 repeated tests are $2.87 \mathrm{~J}$ and $0.49 \mathrm{~J}$, respectively. It is noted that the mean values are displayed at the top bar.
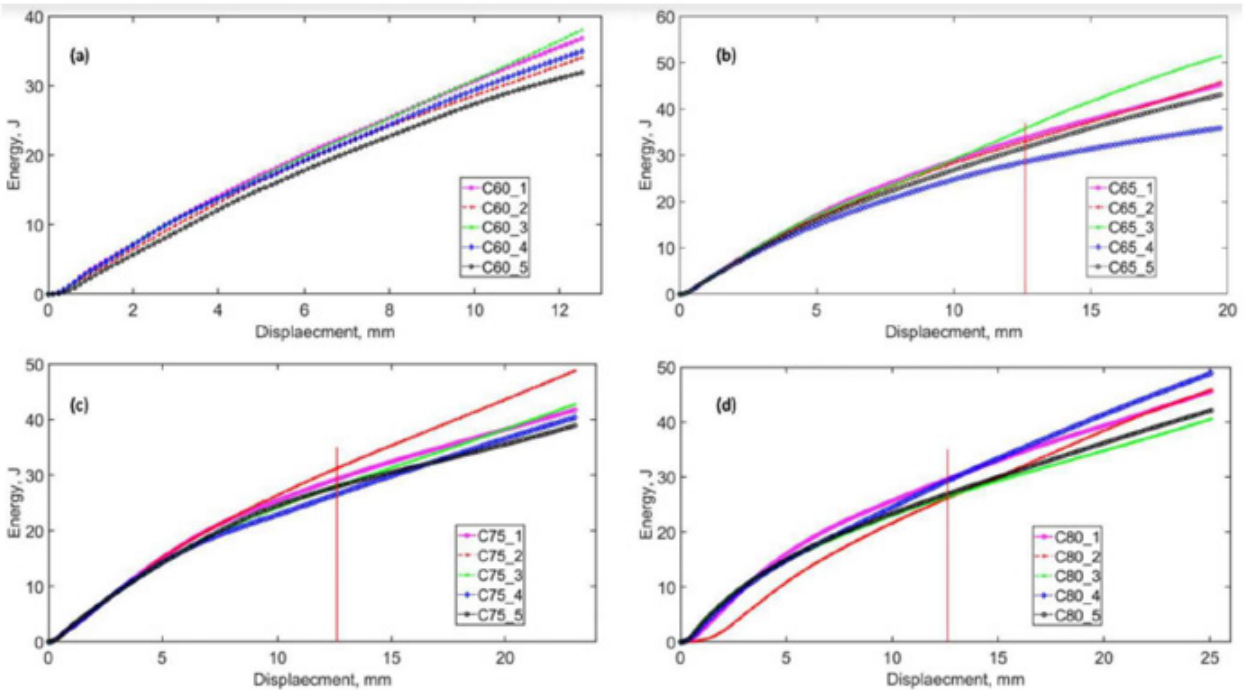

Figure 8: Absorb crash energy of specimens with different outer width.
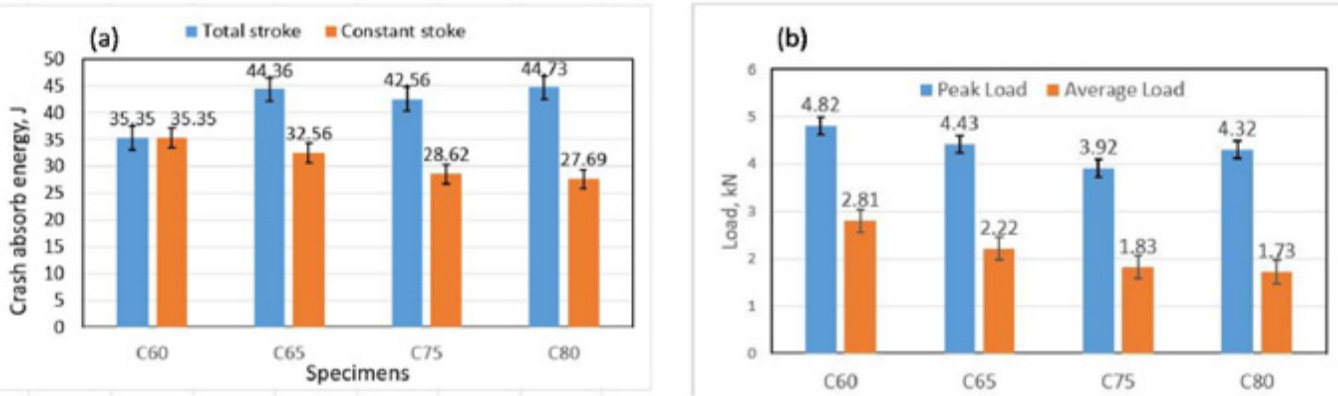

Figure 9: (a) Crash absorb energy and (b) peak compressive load of specimens with different outer width.

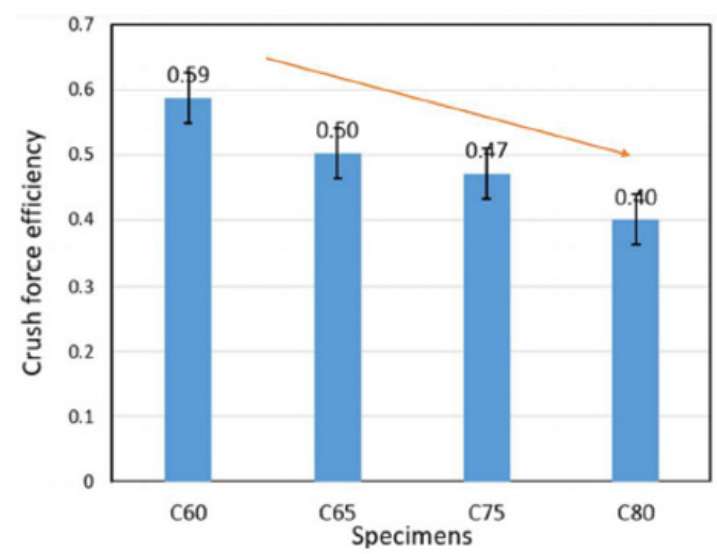

Figure 10: Crush force efficiency of specimens with different outer width. 
Figure 10 shows the results of the crush force efficiency (CFE). The CFE is defined as the ratio of the average load and the peak load. The CFE describes the catastrophic failure or progressive failure mechanism of the specimens. It is noted that, the catastrophic failure is defined as the lowest values of the crush force efficiency (CFE). As shown in Figure 10, the CFE decreases as the specimen width increases. Furthermore, the CFE decreases $31.87 \%$ when the width increases from $\mathrm{C} 60$ to $\mathrm{C} 80$. The results confirm that the CFE of $\mathrm{C} 80$ is catastrophic failure. The average deviation over 5 repeated tests is 0.077 .

Figure 11 shows the results of the specific absorption energy (SAE). The SAE is defined as the absorbed energy per unit mass of the specimen. As shown, the SAE decreases with the increase of the specimen width. Furthermore, the SAE decreases $52.88 \%$ as the width increases from $\mathrm{C} 60$ to $\mathrm{C} 80$. The $\mathrm{C} 60$ specimen presents the highest performance of energy absorption capacity. It worth to mention that the thin-wall square tubes have been widely used as energy absorbers because of their high specific energy absorption capacity and long stroke [15]. The average standard deviation over 5 repeated tests is 398.27J. Figure 12 shows the results of the maximum compressive stress. The maximum compressive stress is defined as the ratio of the peak load and the cross-section area. As shown, the maximum stress decreases $33.54 \%$ as the specimen width increases from C60 to C80. The average standard deviation over 5 repeated tests is $0.639 \mathrm{Mpa}$.

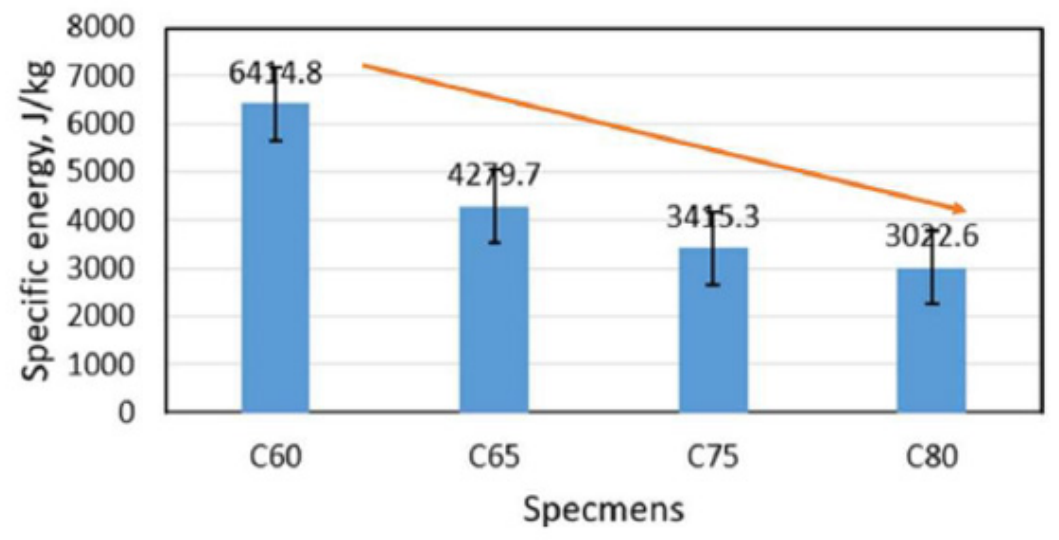

Figure 11: Specific absorption energy of specimens with different outer width.

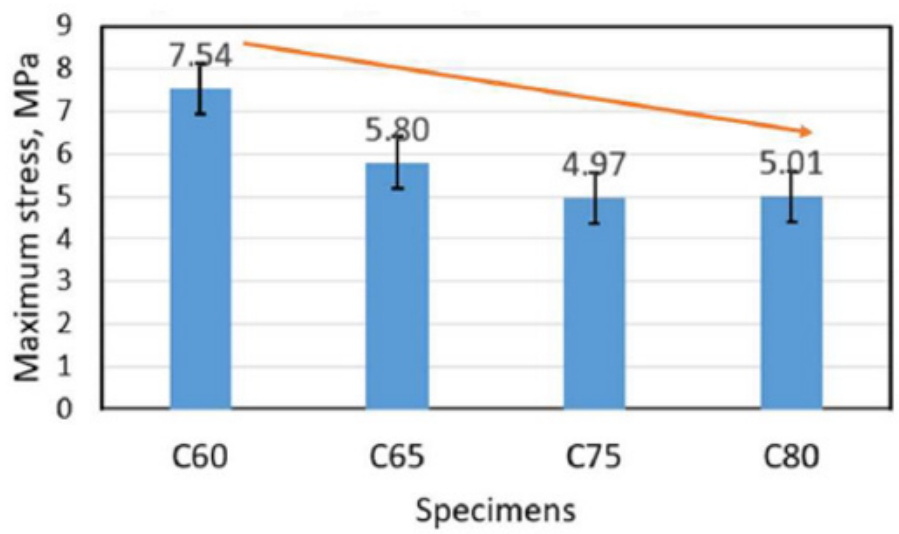

Figure 12: Maximum compressive stress of specimens with different outer width.

\section{Conclusion}

This study focused on characterization of mechanical and energy absorption of the square paper tube under quasi static compression test. The displacement-force curve is obtained to evaluate the buckling failure properties. The results show that the load varies linearly with the displacement in the pre-crushing zone, sudden drop in the pos-crushing zone and stable in the compact zone. The effects of the specimen out width with the peak compressive load and energy absorption also obtained. The buckling failure is occurred at top end, mid-length, and bottom-end of the specimens. The results show that the peak load decrease as the width increases, while the energy absorption increases with the width. Furthermore, the results also show that the main factors of crash failure are the buckling and delamination of the square paper tube. Square paper tubes have the characteristics of a ductile material and can withstand long-stroke destructive compression. 
A further study the correlation of the width and other parameters included the peak compressive load ( $P$ max), crush force efficiency (CFE), and specific absorption energy (SAE) are also presented. The results confirmed that Pmax, CFE, and SAE decreases as the width increases. The results obtained in this study provides an important information of the effect of the width to the mechanical and energy absorption of the square paper tubes. In the future, more detail study the effects of the geometrical parameters to the factors of manufacturing process will be performed to improve the absorption and crashworthiness capability of square paper tubes.

\section{Acknowledgement}

The author grateful acknowledge the square tube samples support provided to this study by Bae Chaur Co. Ltd., Taiwan.

\section{Conflict of interest}

No conflicts of interest, financial or otherwise, are declared by the authors.

\section{References}

1. Ban S, Shodhan K (2003) Tube Housing, Perspecta 34: 154-159.

2. Mamalis AG, Manolakos D, Viegelahn G (1989) The axial crushing of thin PVC tubes and frusta of square cross-section, International Journal of Impact Engineering 8(3): 241-264.

3. Petutschnigg AJ, Ebner M (2007) Lightweight paper materials for furniture-A design study to develop and evaluate materials and joints, Materials \& design 28(2): 408-413.

4. Preston SJ, Bank LC (2012) Portals to an Architecture: Design of a temporary structure with paper tube arches, Construction and Building Materials 30: 657-666.

5. Zhang $\mathrm{X}, \mathrm{Su} \mathrm{H}, \mathrm{Yu} \mathrm{T}$ (2009) Energy absorption of an axially crushed square tube with a buckling initiator, International Journal of Impact Engineering 36(3): 402-417.

6. Cripps A (2004) Cardboard as a construction material: a case study, Building Research \& Information 32(3): 207-219.

7. Oxman R, Oxman R (2010) New structuralism: design, engineering and architectural technologies, John Wiley \& Sons, Ltd.

8. Correa C (2004), Designing with paper tubes, Structural engineering international 14(4): 277-281.
9. Spottiswoode AJ, Bank LC, Shapira A (2012) Investigation of paperboard tubes as formwork for concrete bridge decks, Construction and Building Materials 30: 767-775.

10. Harries KA, Sharma B (2019) Nonconventional and vernacular construction materials: Characterization, properties and applications, Woodhead Publishing, Cambridge, United States.

11. Gerhardt T (1990) External pressure loading of spiral paper tubes: theory and experiment, ASME Journal of Engineering Materials and Technology 112: 144-150.

12. Beatty M, Cheng W (1980) Axial compression of a helically wound, laminated paper tube, Journal of Composite Materials 14(1): 42-56.

13. Czechowski L, Bieńkowska M, Szewczyk W (2018) Paperboard tubes failure due to lateral compressionexperimental and numerical study, Composite Structures 203: 132-141.

14. Cai M, Holst J, Rotter JM (2002) Buckling strength of thin cylindrical shells under localized axial compression. EM2002, 15th ASCE Engineering Mechanics Conference, New York.

15. Hull D (1991) A unified approach to progressive crushing of fibrereinforced composite tubes, Composites science and technology 40(4): 377-421.

16. Harte AM, Fleck NA, Ashby MF (2000) Energy absorption of foamfilled circular tubes with braided composite walls, European journal of mechanics-A/Solids 19(1): 31-50.

17. Mamalis AG, DE Manolakos, MB Ioannidis, DP Papapostolou (2005) On the response of thin-walled CFRP composite tubular components subjected to static and dynamic axial compressive loading: experimental, Composite Structures 69(4): 407-420.

18. Schultz MR (1998) Energy absorption capacity of graphite-epoxy composite tubes. Master Thesis, Virginia Tech.

19. Mamalis AG, DE Manolakos, MB Ioannidis, DP Papapostolou (2004) Crashworthy characteristics of axially statically compressed thin-walled square CFRP composite tubes: experimental, Composite Structures 63(3-4): 347-360.

20. Ataollahi S, ST Taher, RA Eshkoora, AK Ariffina, CH Azhari (2012) Energy absorption and failure response of silk/epoxy composite square tubes: Experimental. Composites Part B: Engineering 43(2): 542-548.

21. Oshkovr S, RA Eshkoor, ST Taher, AK, Ariffin, CH Azhari (2012) Crashworthiness characteristics investigation of silk/epoxy composite square tubes, Composite Structures 94(8): 2337-2342.

22. Lian XG, Liao Pan, Li-Xin Lua, Jun Wang (2020) Investigation of energy absorption characteristics of square paper tubes subjected to axial loading, Thin-Walled Structures 150: 106685. 